\title{
Bioprospección de enzimas de restricción en bacterias de suelos y ambientes volcánicos de Nicaragua
}

\section{Julio A. Gómez-Rodríguez y Jorge A. Huete-Pérez}

Centro de Biología Molecular (CBM). Facultad de Ciencia, Tecnología y Ambiente. Universidad Centroamericana, Rotonda Rubén Darío, 500 mts al oeste, Apto. Postal 69. Managua, Nicaragua. Tel: 278-3923 Ext. 1189. Correo electrónico: juliogomer@gmail.com, huete@ns.uca. $\underline{\text { edu.ni }}$

Recibido: octubre de 2008 / Aceptado: noviembre de 2008

LA BIOPROSPECCIÓN ES LA BÚSQUEDA SISTEMÁTICA DE USOS SOSTENIBLES y con fines comerciales de los elementos genéticos y bioquímicos de la biodiversidad. En Nicaragua realizamos bioprospección de enzimas de restricción (ER) de interés biotecnológico desde el año 1999. A través de esta investigación buscamos nuevas ER en bacterias de suelos en ambientes aún inexplorados, como zonas volcánicas y agrícolas del país. Aquí reportamos la identificación de isoesquizómeros de 14 ER conocidas: BamHI, EcoRV, MboI, MaeI, HaeIII, EarI, BsoBI, BsaBI, Acl I, BsaWI, Nci I, BstNI, BssSI y HpaII, las 8 últimas termoestables. La información de las ER encontradas en Nicaragua fue registrada en REBASE (Restriction Enzyme Database). Resaltamos la importancia del estudio de la biodiversidad microbiana de los ambientes volcánicos nicaragüenses, ya que favorece la investigación de la evolución de la vida, los extremos donde podemos encontrarla y sus aplicaciones a la biotecnología.

Palabras clave: enzimas de restricción / biotecnología / bioprospección / ambientes volcánicos

\section{Introducción}

Nicaragua pertenece a uno de los bloques de mega diversidad del mundo. Se considera que por ser un puente geográfico posee una posición tropical privilegiada que se traduce en más de 20 diferentes ecosistemas ricos en biodiversidad. Este país de 132,000 Km² -que representa tan sólo el $0.13 \%$ de la superficie terrestre mundial- posee el 7\% de la flora, fauna y diversidad geográfica de todo el planeta (MARENA, 1999).

La bioprospección es la búsqueda sistemática de usos sostenibles y con fines comerciales de los elementos genéticos y bioquímicos de la biodiversidad. Se ha propuesto que un programa estratégico de bioprospección permitiría la conservación de muestras representativas de 
los ecosistemas, conocer la biodiversidad existente y finalmente emplear estos recursos para el desarrollo socioeconómico (Guevara, 2002).

En abril de este año se realizó el IV Congreso Nicaragüense de Biotecnología, cuyo invitado de honor fue el Dr. Richard J. Roberts, galardonado con el Premio Nobel de Fisiología y Medicina en 1993. En su conferencia magistral, el Dr. Roberts presentó las diversas oportunidades para países en vías de desarrollo como Nicaragua, de tener un papel relevante en la ciencia a nivel mundial. Recalcó que Nicaragua, con una biodiversidad prácticamente desconocida y poco estudiada, podría albergar especies de mucho interés para la ciencia y que con el advenimiento de la genómica todo el acervo genético de la biodiversidad será de mucha utilidad en el futuro. Así, un gen aislado en alguna especie endémica de Nicaragua podría tener aplicaciones en las ciencias biomédicas y en la industria biotecnológica. El Dr. Roberts recomendó compartir los conocimientos y hallazgos científicos con la comunidad científica internacional a través de bases de datos.

Desde 1999 el Centro de Biología Molecular de la UCA (CBM-UCA) inició un proyecto de investigación en bioprospección. Se buscaron enzimas de restricción (ER) en bacterias de suelos nicaragüenses. Se muestreó especialmente la zona central del pacífico, donde se encontró ER en el 25\% de las muestras analizadas (Roustan-Espinosa et al., 2000). Conociendo que Nicaragua posee una variedad de ambientes y que la gran mayoría permanece aún inexplorada, en el presente estudio se amplió el área de muestreo hacia las zonas cafetaleras y bosques de pino de Nueva Segovia y zonas azucareras y volcánicas del occidente del país.

Las ER son herramientas moleculares que cortan el ADN (ácido desoxirribonucleico) en sitios específicos. Werner Arber, Daniel Nathans y Hamilton Smith compartieron el Premio Nóbel de Medicina por el descubrimiento de las ER y su aplicación al análisis molecular del ADN en 1978 (Watson et al., 2004). Las ER han demostrado ser invaluables para el desarrollo de mapas físicos del $\mathrm{ADN}$ de cualquier organismo, de diagnóstico genético y de la tecnología del ADN recombinante. Todas estas técnicas son las bases de la biología molecular moderna (Roberts, 2005).

El objetivo principal de esta investigación fue encontrar nuevas ER. La comercialización de enzimas nuevas patentables le permitiría al CBM-UCA contar con fondos para continuar y diversificar sus áreas de investigación en bioprospección.

La biprospección de ER o de genes utilizando la micro-biodiversidad, tal y como se presenta en este trabajo, podría servir de mucho en términos económicos así como para fines de investigación y entrenamiento científico en Nicaragua.

\subsection{Historia y usos de las ER}

A partir de la década de 1970 se empezó a utilizar las ER como herramientas fundamentales para el análisis de ADN. Los principales usos reportados para las ER son:

La preparación de moléculas de ADN recombinante y clonación molecular. Se utilizan ER para reconocer secuencias de genes específicas y luego reinsertar fragmentos en el 
genoma de otro organismo usando un vector apropiado. De este modo se aprovechan las propiedades de especificidad y la producción de extremos cohesivos por algunas ER (Watson et al., 1992:63-77).

Otro importante uso de las ER se dio en los primeros días de la secuenciación de ADN con el uso de los fragmentos de restricción debido a que facilitó el manejo de éstos. Además, los métodos de secuenciación química desarrollados por Wally Gilbert y Allan Maxam también dependieron de las ER al proveer el único extremo 5', que podía ser marcado con el isótopo radiactivo $32^{\mathrm{P}}$ (Roberts et al., 2005).

Danna y Nathans dilucidaron desde un principio que los fragmentos producidos por la digestión con ER serían útiles para preparar mapas físicos de distintos genomas o mapas de restricción. Mostraron también que se podía localizar el origen de replicación y la posición específica de algunos genes (Roberts et al., 2005).

Cortando el ADN de un plásmido con una ER que reconoce sólo un sitio, se produce una molécula lineal. Éste sirve como un punto de entrada para la modificación de la secuencia de ADN en la vecindad del sitio de restricción, permitiendo el simple acceso para provocar mutagénesis (Watson et al., 1992:193-94).

La combinación de la técnica de reacción en cadena de la polimerasa (PCR) para la amplificación de cualquier segmento de ADN y la especificidad de secuencias de las ER, ha facilitado el análisis de cambios en las secuencias de ADN en células tumorales. De este modo, si la mutación ocurre en el sitio de restricción de una ER, ésta perderá la habilidad para reconocer la secuencia de $\mathrm{ADN}$ debido a la pérdida del sitio de restricción. Sin embargo, es posible examinar mutaciones que crean nuevos sitios de restricción. El estatus de metilación de los genes puede ser determinado con ER y finalmente los eventos de deleción alélica pueden ser detectados a través de la pérdida de sitios de restricción (Jenkins et al., 2002).

Las endonucleasas de sitio específico son ampliamente usadas en el análisis y reestructuración de moléculas de ADN y como sistema modelo para el estudio de interacciones de ADN-proteínas (Whitehead \& Brown ,1985), a la vez que juegan un papel indispensable en la manipulación de $\mathrm{ADN}$ recombinante y como modelos para el estudio de la estructuras proteínicas y mecanismos catalíticos (Qing et al., 2000).

Se han desarrollado diversas técnicas de genética molecular basadas en el uso de las ER. Entre éstas vale la pena considerar: RFLP, AFLP, PFGE, RSM Y PCR/REA (ver Cuadro 1). 
Cuadro 1. Técnicas de genética molecular basadas en el uso de las ER

\begin{tabular}{|c|c|}
\hline Nombre de la técnica & Aplicación en genética molecular \\
\hline $\begin{array}{l}\text { RFLP (Restriction Frag- } \\
\text { ment Length Polymor- } \\
\text { phisms) }\end{array}$ & $\begin{array}{l}\text { Primer método de tipificación de ADN usado en las pruebas } \\
\text { de identidad humanas (Budowle } \text { et al., 2000). } \\
\text { De amplio uso en Genética Forense, identificación de } \\
\text { organismos, como marcadores para análisis de ligamiento } \\
\text { genéticoyestudios de genética poblacionalyde enfermedades } \\
\text { hereditarias (Watson et al., 1992:519-535). }\end{array}$ \\
\hline $\begin{array}{l}\text { AFLP (Amplified Frag- } \\
\text { ment Length Polymor- } \\
\text { phisms): }\end{array}$ & $\begin{array}{l}\text { Combina el uso de ER y la reacción en cadena dela polimerasa } \\
\text { (PCR) (Geornaras et al., 1999). Ha sido aplicada para } \\
\text { estudiar la variación genética existente en las poblaciones } \\
\text { naturales de Pinus oocarpa de Nicaragua, usando dos ER } \\
\text { (MseI y PstI) (Díaz et al., 2001). }\end{array}$ \\
\hline $\begin{array}{l}\text { PFGE (Pulsed Field Gel } \\
\text { Electrophoresis): }\end{array}$ & $\begin{array}{l}\text { Técnica de oro estándar de los métodos de identificación } \\
\text { molecular del ADN cromosómico total. Se usa para separar } \\
\text { fragmentos de } 10 \text { a 800kb. Los datos son analizados con } \\
\text { paquetes informáticos. La desventaja es que los resultados } \\
\text { se obtienen en dos a tres días, lo que limita el análisis de una } \\
\text { gran cantidad de muestras (Olive \& Bean, 1999). }\end{array}$ \\
\hline $\begin{array}{l}\text { RSM assay (Restriction } \\
\text { Site Mutation Assay) }\end{array}$ & $\begin{array}{l}\text { Muy útil para estudiar la prevalencia de mutaciones en } \\
\text { codones calientes que son claves en genes relacionados a } \\
\text { tumores (Jenkins et al., 2002). }\end{array}$ \\
\hline $\begin{array}{l}\text { PCR/REA (Polymerase } \\
\text { Chain Reaction/ Restric- } \\
\text { tion Enzyme Analysis): }\end{array}$ & $\begin{array}{l}\text { El método es basado en la amplificación de la región variable } \\
\text { del gen RNAr } 23 \mathrm{~S} \text { ribosómico seguido por la digestión con } \\
\text { dos ER. Según Engvall et al. (2002), el método es fácil de } \\
\text { desarrollar y su poder de discriminación es alto ya que } \\
\text { permite la identificación y diferenciación de especies } \\
\text { bacterianas cercanamente relacionadas. }\end{array}$ \\
\hline
\end{tabular}

\section{Materiales y métodos}

Todos los procedimientos experimentales de este estudio se llevaron a cabo en el Centro de Biología Molecular de la Universidad Centroamericana (CBM-UCA). Las ER comerciales, los distintos tipos de $\mathrm{ADN}$ usados para los ensayos enzimáticos y los tampones usados para realizar las digestiones enzimáticas se obtuvieron de New England Biolabs, Inc., Estados Unidos.

Con algunas modificaciones, el procedimiento experimental fue establecido en el CBM en base a Roustan et al. (2000) y Greene \& Heyneker (1978) (ver Ilustración 1). 

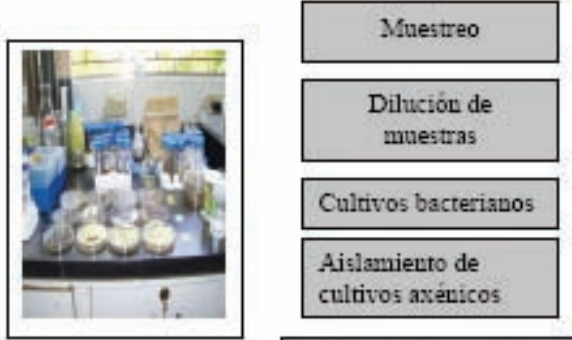

Cultivos bacterianos

Aislamieuto de cultivos axénicos

\section{Obtención de extracto enzimático}
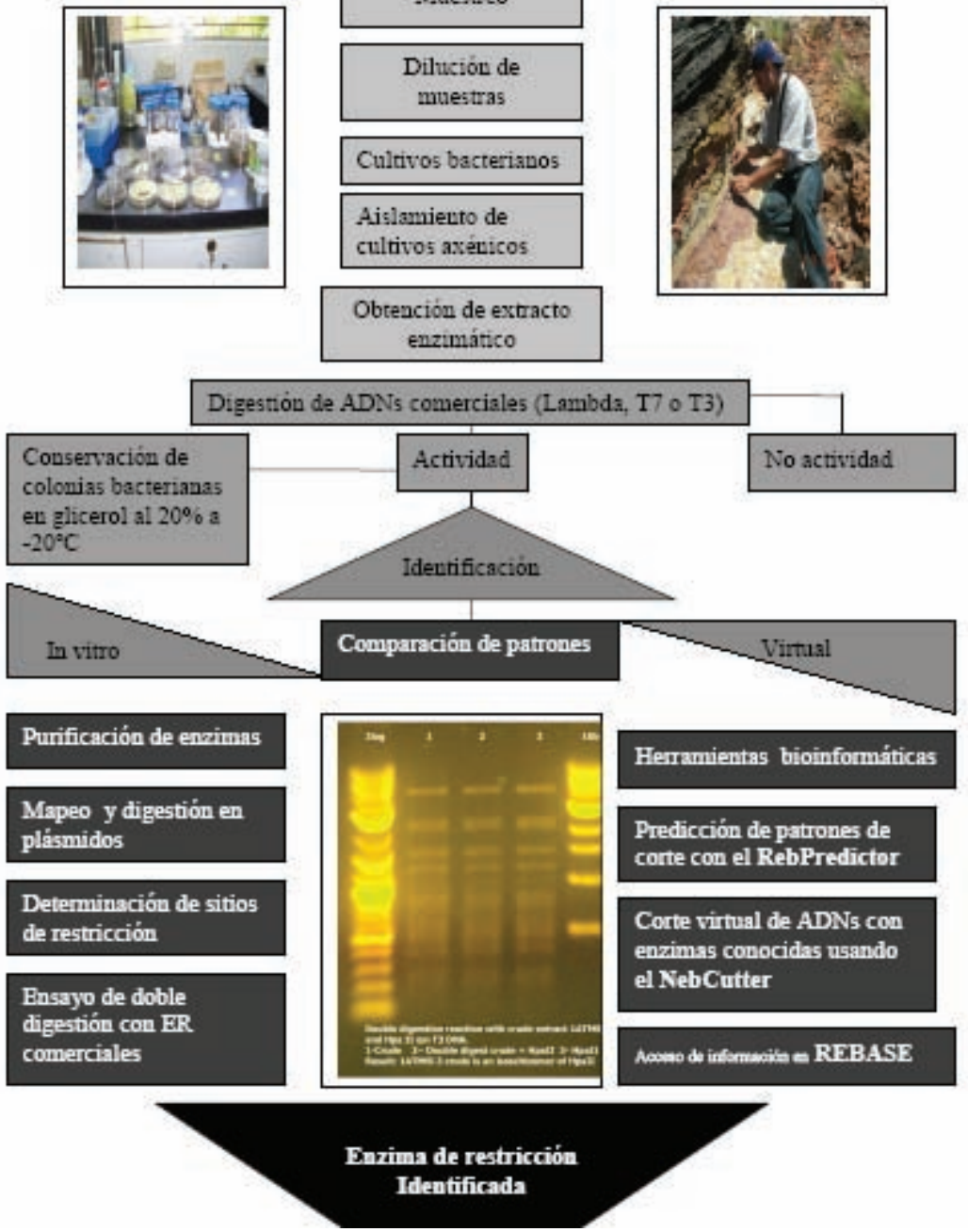

Ilustración 1. Metodología empleada para la identificación de ER

\subsection{Muestreo y tratamiento de las muestras}

Se realizaron ocho giras de campo y se colectó un total de 50 muestras procedentes de Dipilto, Ocotal y Mozonte, todos municipios del departamento de Nueva Segovia; de Tonalá y Chinandega, parte de la cordillera de volcanes Los Maribios; y de los Hervideros de San Jacinto, ubicados en el departamento de León (ver Ilustración 2). 
Microlocalización muestreo Norte
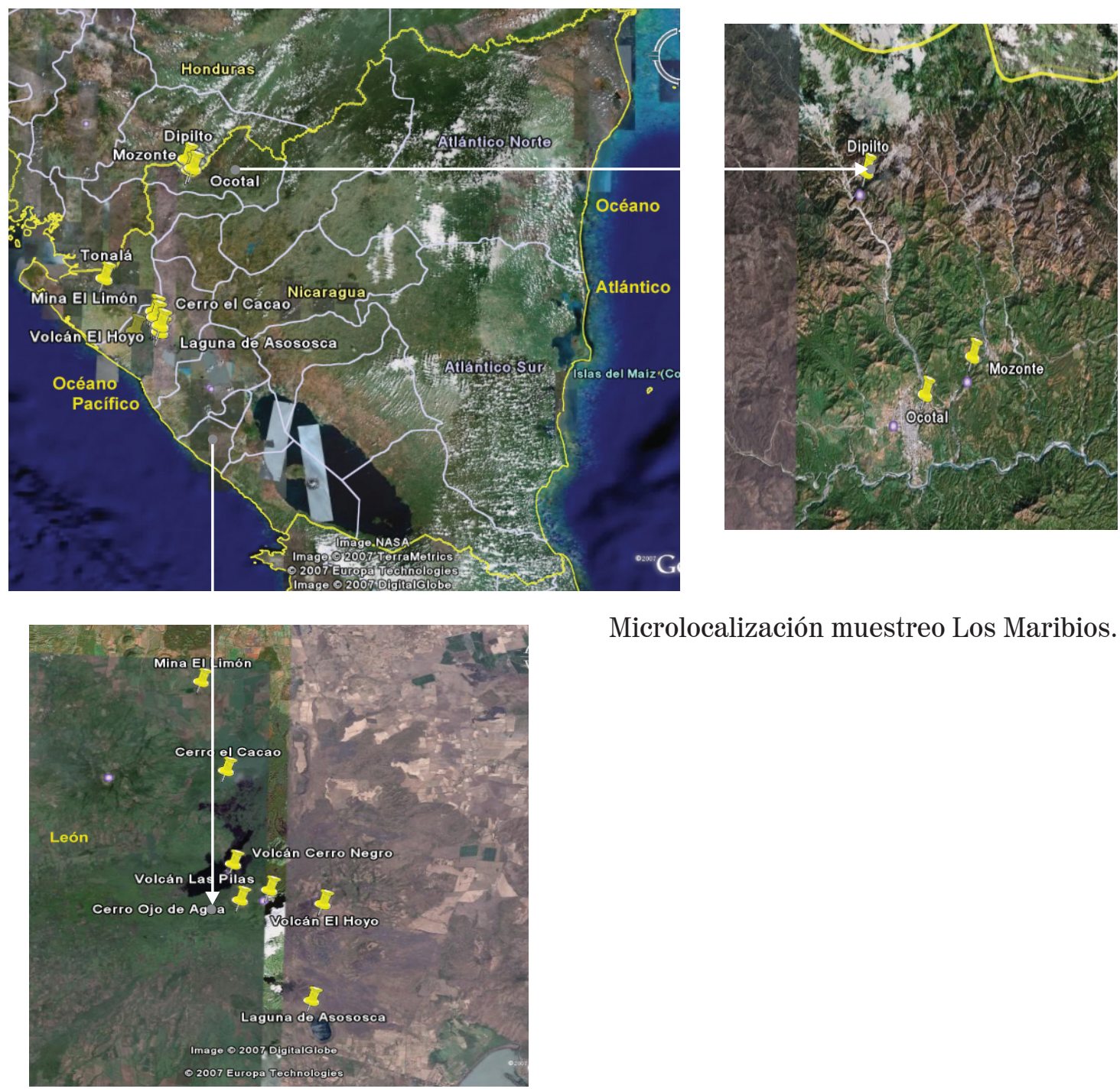

Microlocalización muestreo Los Maribios.

Ilustración 2. Mapa de Nicaragua con los sitios de muestreo. Al norte de Nicaragua en Ocotal, Mozonte y Dipilto. En el pacífico, en la cordillera de volcanes Los Maribios, en León y en Tonalá, Chinandega.

Tomado de Europa Technologies LTD (2007)

Para obtener poblaciones bacterianas autóctonas, en el muestreo se seleccionaron sitios poco alterados y alejados de la influencia humana. Se describió con precisión las principales características del lugar y el tipo de suelo, además se tomaron suelos fácilmente distinguibles por su color, textura y por el tipo de vegetación. Para las muestras tomadas en los Hervideros de San Jacinto en febrero de $2007^{1}$, se midió el pH utilizando papel indicador obtenido de Fisher, Estados Unidos, y se midió la temperatura con un termómetro de mercurio Bannan, 
Inglaterra de escala máxima de $200^{\circ} \mathrm{C}$. Para la colección de las muestras se usó tubos Falcon estériles de $50 \mathrm{ml}$ que se llenaron con tierra superficial hasta $40 \mathrm{ml}$. Cada muestra fue debidamente codificada. En el laboratorio se trasladó $10 \mathrm{ml}$ de las muestras a otro tubo y luego se diluyó con solución de $\mathrm{NaCl}$ al 1\% hasta los 50ml. Esta solución se utilizó como solución madre a partir de la cual se prepararon diluciones de 1/15 y 1/30 para cada muestra.

\subsection{Cultivos bacterianos y condiciones de crecimiento}

El medio de cultivo utilizado para crecer las bacterias fue LB agar Miller (cloruro de sodio $10 \mathrm{~g}$, triptona de soya $10 \mathrm{~g}$ y extracto de levadura $5 \mathrm{~g}$, por litro de medio preparado) y se obtuvo de Sigma, Estados Unidos. Como agente solidificante se usó Select Agar (Gibco BRL, Escocia). Los medios de cultivo fueron esterilizados en autoclave a $121^{\circ}$ por 30 minutos y vertidos en platos petri desechables.

Con el propósito de obtener la mayor cantidad y diversidad de colonias bacterianas en los medios de cultivo, se diseñó un experimento, preparando cultivo enriquecido con suelo nativo. Para ello, solamente se le agregó a la mezcla del cultivo LB (para 250mL de medio de cultivo: 3.5gr de agar, 6.5gr de LB) el equivalente en gramos del 1\% de suelo. La hipótesis consiste en que los nutrientes naturales del suelo, presentes en cada muestra, pueden favorecer el crecimiento de mayor número de diferentes colonias bacterianas autóctonas, las cuales utilizan naturalmente estos nutrientes. Para el cultivo de bacterias termófilas se varió el protocolo de cultivo, ya que según el Dr. Morgan de New England Biolabs, estas bacterias crecen mejor en medio de cultivo con escasez de nutrientes (comunicación personal). Así se redujo en un 50\% la adición de LB al medio. También, debido a las altas temperaturas de crecimiento, a los cultivos para termófilos se le agregó un 60\% más de agar para lograr mayor solidez en el medio de cultivo. Aún con los cambios realizados no se logró cultivar bacterias de muestras colectadas a temperaturas superiores a los $65^{\circ} \mathrm{C}$. Para este tipo de cultivo se recomienda usar gelrite, un agente solidificante especial para cultivos termófilos. Todas las muestras sin excepción fueron cultivadas sin control de dióxido de carbono, oxígeno ni humedad en la incubadora.

\subsection{Selección, aislamiento y cultivo de colonias bacterianas}

Después de18 horas se observó el crecimiento en la placa de cultivo, se describió cuántas y qué tipos de colonias fueron encontradas en cada muestra, se enumeraron y se aislaron colonias individuales.

\subsection{Obtención de extracto celular o crudo}

Obtenido el cultivo axénico o puro de cada colonia bacteriana, se procedió a resuspender el material celular con 4ml del tampón de lisis (Tris- HCl 20mM, EDTA 0.5mM, NaCl 50mM, DTT 1mM, pH: 7.5). Para obtener el contenido intracelular se le agregó PMSF (Sigma) a una concentración de $6 \mathrm{mg} / \mathrm{ml}$ como inhibidor de serino-proteasas. Se obtuvo un volumen de suspensión de $4 \mathrm{ml}$ en un tubo de micro centrífuga de $15 \mathrm{ml}$ (Fisherbrand). Para una lisis completa, la suspensión se sonicó con el procesador de ultrasonidos (UltrasonicProcesor) 
en modo continuo cuatro veces por períodos de $40 \mathrm{seg}$. a una potencia de 5 watts/seg. La suspensión se transfirió a tubos de micro centrífuga de $1.5 \mathrm{ml}$ y se centrifugó a $14000 \mathrm{rpm}$ a $4^{\circ} \mathrm{C}$ por nueve minutos. Se descartó el pellet y se tomó el sobrenadante (extracto o crudo) que se usó para los ensayos enzimáticos.

\subsection{Ensayos enzimáticos}

\section{Ensayo general}

A continuación se describen los procedimientos generales para realizar los diferentes ensayos, los cuales tienen como fin la identificación de las actividades enzimáticas encontradas. Se preparó una mezcla de reacción con agua desionizada, tampón NEB, ADN y se le agregó $12 \mu \mathrm{l}$ de extracto crudo. Generalmente, para el ensayo se utilizan dos tipos de ADN: Lambda y T7 o T3 debido a que la mayoría de las ER conocidas cortan el ADN de estos bacteriófagos. Para el ensayo general se usa siempre el tampón NEB 2. La reacción se detuvo agregando $10 \mu \mathrm{l}$ del búfer 6x (azul de bromofenol 0.25\%, glicerol al 30\%).

Si en el ensayo general se observaba actividad, se procedió a probar en cuál tampón NEB $(1,2,3$ ó 4) la enzima presentaba mejor actividad y una digestión completa. Ver Cuadro 2 e Ilustración 3, en la que se observa que es en el tampón 4 en el que la enzima presenta una actividad completa y más clara. Identificado el búfer apropiado se preparan las mezclas de reacción para digerir cada $\mathrm{ADN}$ comercial con el objetivo de tener varios patrones de corte y compararlos con los patrones de digestión disponibles en el catálogo NEB 2002 (ver Ilustración 3).

Cuadro 2. Composición de los tampones NEB (10X)

Tampón 1(amarillo)

$\overline{10 \mathrm{mM} \text { Bis }}$ Tris Propane-HCL, $10 \mathrm{mM} \mathrm{MgCl} 2,1 \mathrm{mM}$ DTT, pH 7.0 a $25^{\circ} \mathrm{C}$

Tampón 2(azul)

$\overline{10 \mathrm{mM} T}$ ris $\mathrm{HCl}, 10 \mathrm{mM} \mathrm{MgCl} 2,50 \mathrm{mM} \mathrm{NaCl}, 1 \mathrm{mM}$ DTT, pH 7.9 a $25^{\circ} \mathrm{C}$

Tampón 3(rojo)

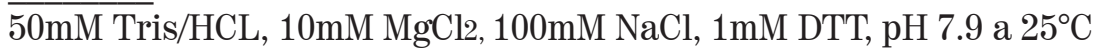

Tampón 4(verde)

$\overline{50 \mathrm{mM} \mathrm{KOAc}}$, 20mM Tris-OAc, $10 \mathrm{mM} \mathrm{Mg}$ ( OAc)2, $1 \mathrm{mM}$ DTT, pH 7.9 a $25^{\circ} \mathrm{C}$

New England Biolabs provee de tampones NEB etiquetados con color para cada ER para asegurar una actividad óptima (100\%) 


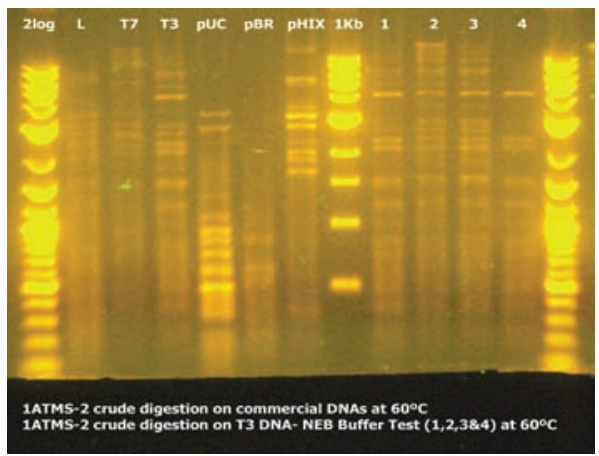

Ilustración 3. Digestión de todos los ADN con el extracto de 1ATMS-3 (izquierda). Los ADNs de bacteriófagos digeridos son L:lambda, T7 y T3. Los ADNs de plásmidos digeridos son pUC19, pBR322 y pHIX174. Ensayo de los buffers NEB (1, 2, 3 y 4) en el ADN T3 (derecha). $2 \log$ y $1 \mathrm{~Kb}$ son marcadores de peso molecular.

\section{Ensayo de purificación}

Los métodos para purificar proteínas son variados y se basan en las propiedades esenciales de éstas: forma, tamaño, carga neta y bio-propiedades como la afinidad a anticuerpos (Coligan et al.2003). En este estudio se utilizaron dos métodos: 1) purificación en base a la carga neta de la proteína, para el cual usamos una matriz de DEAE52 (diethylaminoethyl cellulose) que es una matriz de intercambio aniónico y 2) columnas de Heparina, que es un método de cromatografía de afinidad. Ambos fueron útiles para algunas de las enzimas encontradas. La purificación de las enzimas del extracto crudo es realizada inicialmente a través de una columna con una matriz de Heparina (Hi Trap Hp, Amersham Biosciences, Suecia) y en caso necesario con DEAE52 (Whatman, England). Se utilizó una bomba de purificación (Pharmacia, model LKB-Pump 1, Suecia) a una razón de flujo de $2 \mathrm{ml} / \mathrm{min}$. Las proteínas fueron eluídas en un gradiente de $\mathrm{NaCl}$ desde $50 \mathrm{mM}$ búfer A (Tris-HCl 20mM, EDTA $0.5 \mathrm{mM}$, NaCl 50mM, DTT 1mM, BME 10mM, glicerol al 5\%) hasta $1 \mathrm{M}$ del búfer B (Tris-HCl 20mM, EDTA 0.5mM, NaCl 1M, DTT 1mM, BME 10mM, glicerol al 5\%) obteniendo aproximadamente 25 alícuotas o fracciones de $3 \mathrm{ml}$ cada una. Las fracciones obtenidas en la purificación son ensayadas generalmente con los ADN Lambda o T7 e incubadas a la temperatura apropiada $\left(37,55\right.$ y $\left.60^{\circ} \mathrm{C}\right)$ por un período de 30 minutos.

Utilizando estos métodos de purificación, logramos separar dos diferentes ER procedentes de la misma colonia bacteriana. En la Ilustración 4 se puede observar la actividad de restricción de las fracciones 5 a la 12 en el ADN de Lambda. Sin embargo, éste es un comportamiento inusual ya que se espera que la actividad se observe como máximo en tres fracciones, no en ocho como en este caso. Este dato nos sugirió que había dos ER y luego ensayamos las fracciones 5 y 12 por separado, dando patrones de corte diferentes. De estas digestiones logramos identificar a las ER termoestables BsaBI (fracción 12) y BsoBI (fracción 5) (ver Cuadro 3 e Ilustración 4). 
Cuadro 3. Isoesquizómeros de ER encontradas en Nicaragua y su código de acceso en REBASE

\begin{tabular}{|c|c|c|c|}
\hline Isoesquizómeros & Sitio de muestreo & $\mathrm{T}^{\circ} \mathrm{C}$ Incubación & Código REBASE \\
\hline Mbo I & Ocotal, NS. & 37 & UbaN1 \\
\hline Hae III & Ocotal, NS. & 37 & UbaN2 \\
\hline Bam HI & Dipilto, NS. & 37 & UbaN3 \\
\hline Eco RV & Tonalá, Chin. & 37 & UbaN4 \\
\hline$B f a \mathrm{I}$ & Cerro Negro, León & 37 & UbaN5 \\
\hline$B s a \mathrm{~B} \mathrm{I}$ & Cerro Negro, León & 55 & UbaN6 \\
\hline BsoB I & Cerro Negro, León & 55 & UbaN7 \\
\hline EarI & Teotecacinte, NS. & 37 & UbaN8 \\
\hline Hae III & Teotecacinte, NS. & 37 & UbaN9 \\
\hline$A c l \mathrm{I}$ & $\begin{array}{l}\text { Hervideros de San } \\
\text { Jacinto, Leon. }\end{array}$ & 60 & UbaN10 \\
\hline BsaW I & $\begin{array}{l}\text { Aguas termales } \\
\text { Macuelizo, NS. }\end{array}$ & 60 & UbaN11 \\
\hline$N c i \mathrm{I}$ & $\begin{array}{l}\text { Hevideros de San } \\
\text { Jacinto, León. }\end{array}$ & 60 & UbaN12 \\
\hline Bst $\mathrm{NI}$ & $\begin{array}{l}\text { Hervideros San } \\
\text { acinto, León }\end{array}$ & 60 & UbaN13 \\
\hline BssSI & $\begin{array}{l}\text { Aguas termales } \\
\text { Macuelizo, NS. }\end{array}$ & 60 & UbaN14 \\
\hline HpaII & $\begin{array}{l}\text { Aguas termales } \\
\text { Macuelizo, NS. }\end{array}$ & 60 & UbaN15 \\
\hline
\end{tabular}




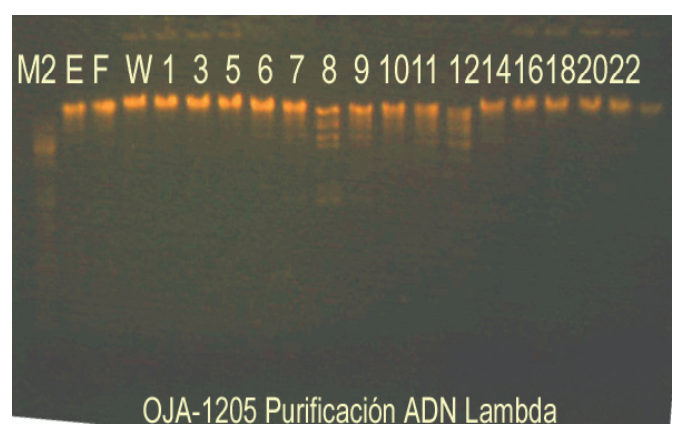

Ilustración 4. Purificación de enzimas M2: Lambda DNA digerido con Bst E II, E: Extracto, F: Flow through o flujo inicial; W: wash o lavado. De 1 a 22 se muestran las distintas fracciones obtenidas, ensayadas en ADN Lambda.

\section{Ensayo de doble digestión}

Para este tipo de ensayo se utiliza en la misma reacción tanto una enzima comercial purificada como la enzima en estudio para digerir el mismo tipo de ADN. Si el patrón de corte coincide, significa que la enzima en estudio es un isoesquizómero de la enzima comercial (ver Ilustración 5).

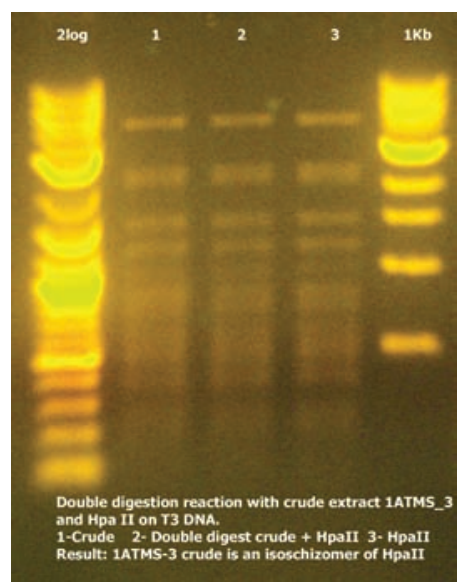

Ilustración 5. Doble digestión de extracto ATMS-3 y la enzima comercial HpaII en el ADN de T3. $2 \log$ y $1 \mathrm{~Kb}$ son marcadores de peso molecular. 1- Digestión del ADN de T3 con el extracto de ATMS-3. 2- Digestión combinada de extracto de ATMS-3 y la enzima comercial HpaII. 3- Digestión de la enzima comercial HpaII en el ADN de T3.

\section{Ensayo de mapeo de restricción en plásmidos}

Es necesario determinar los sitios de corte de una ER en un ADN comercial. Para esto, se prepararon tres reacciones con las mezclas de digestión y se ensayó el extracto junto con una 
enzima comercial diferente que corta el ADN una sola vez, en tres reacciones individuales. Mediante el cálculo del tamaño de las bandas producidas por los cortes simultáneos del extracto y las enzimas comerciales, se puede determinar con un grado de error de +/- 30pb, el sitio de corte de la enzima desconocida. Este proceso sólo puede realizarse si la enzima en cuestión tiene uno o dos sitios de corte en el ADN del plásmido.

\subsection{Chequeo de actividad de restricción por electroforesis en gel de agarosa}

La electroforesis es una técnica ampliamente usada para separar macromoléculas ya sea por su tamaño o por su carga. Las ER, al digerir el ADN, producen fragmentos que se corresponden a un patrón de corte que puede ser observado como bandas fluorescentes de ADN separadas por su tamaño en el gel de agarosa.

\subsection{Preparación del gel de agarosa y corrida electroforética}

Se utilizó agarosa al 1\%, (American Bioanalytical, EU), se disolvió con búfer TBE (Tris base $89 \mathrm{mM}$, ácido bórico $89 \mathrm{mM}$ y EDTA $2 \mathrm{mM}$ para una solución 1X) y se calentó en un horno de microondas por tres minutos, y se le agregó $7 \mu \mathrm{l}$ de bromuro de etidio $(30 \mathrm{mg} / \mathrm{ml})$. Se depositó $15 \mu$ l de la mezcla de digestión con azul de bromofenol y los marcadores de peso molecular I (ADN de Lambda digerido con Hind III, ADN del pHIX 174 con Hae III) y II (ADN de lambda digerido con BstE II). La electroforesis se corrió a 100 voltios por una hora o más.

\subsection{Visualización y foto documentación}

Las bandas de ADN son observables bajo la acción de la luz ultravioleta (UV) debido a que el colorante bromuro de etidio se intercala entre las bases nitrogenadas de la molécula de ADN y fluorece bajo la luz UV. Las fotografías se tomaron con la cámara digital Olympus modelo D600L con filtro para luz UV. Las fotografías son modificadas para su análisis usando el programa Adobe Photoshop 6.0.

\subsection{Uso de herramientas bioinformáticas}

Para identificar con mayor rapidez una ER nos auxiliamos de programas bioinformáticos que permiten la predicción de un patrón de corte (RebPredictor) o que ayudan a realizar digestiones con las enzimas conocidas (NebCutter), así también ayudan a obtener todo tipo de información de alguna ER. Estos programas están disponibles en la página Web de New England Biolabs directamente en http://tools.neb.com.

\subsection{Almacenamiento de colonias bacterianas}

Las colonias bacterianas de las que se aislaron ER fueron almacenadas con el propósito de futuros usos. Las bacterias fueron cultivadas en medio sólido por 12 horas. Luego se resuspendió el material celular con $1 \mathrm{ml}$ de $\mathrm{LB}$ líquido estéril y se transfirió a un tubo eppendorf de $1.5 \mathrm{ml}$. A esto se agregó $300 \mu$ l de glicerol estéril y se mezcló en vortex por dos minutos para lograr la homogeneización de los componentes. Todas las colonias bacterianas debidamente identificadas y rotuladas se almacenaron a $-20^{\circ} \mathrm{C}$ indefinidamente. 


\section{Resultados y discusión}

De los muestreos realizados se analizó un total de 50 muestras de suelos. De éstas, se identificaron 15 ER de las cuales ocho son termoestables. De las ER encontradas, las de mayor importancia y de mayor uso en los laboratorios de biología molecular son: BamHI, EcoRV y HaeIII. Las dos primeras por producir fragmentos de restricción pegajosos útiles para construir $\mathrm{ADN}$ recombinante y la última por ser útil para producir marcadores de peso molecular, esenciales para determinar los tamaños de las bandas de ADN en los experimentos. En las Ilustraciones 3 y 5 se presentan fotografías de geles de agarosa de las digestiones realizadas con la actividad enzimática ATMS-3, que fue identificada como un isoesquizómero de HpaII por doble digestión.

Del Cuadro 3 se puede deducir que se aislaron más enzimas (ocho) de las zonas volcánicas en comparación con las otras zonas de muestreo. Las características distintivas de las zonas volcánicas -como la presencia de mayor cantidad de nutrientes- así como las diferencias de temperatura, parecen permitir una mayor proliferación de diferentes tipos bacterianos y por lo tanto de obtener mayor número de enzimas. El sitio de muestreo que presentó las características de un ambiente extremo y en algunos lugares de hiper-extremo fue en los Hervideros de San Jacinto. Aquí encontramos variaciones de temperatura de 45 a $120^{\circ} \mathrm{C}$ y de $\mathrm{pH}$ de 2.0 a 10.0 .

\subsection{La adición de suelo nativo a los medios de cultivo favorece el crecimiento}

La adición de suelo nativo a los medios de cultivo favoreció la cantidad y diversidad de colonias bacterianas. Lo afirmado se sustenta en las siguientes observaciones: a) En los medios de cultivo enriquecidos con suelo nativo se observó mayor cantidad de colonias bacterianas con diferencias por sus características morfológicas. b) El mayor problema que se observó al realizar cultivos sólo con LB (no enriquecido), fue el crecimiento de colonias bacterianas que se extienden por todo el medio de cultivo, imposibilitando el crecimiento y aislamiento de otras. Este problema fue superado al adicionar suelo nativo al medio de cultivo, ya que estas colonias "satélites" no se observaron más. Esto permitió el aislamiento y diferenciación de las colonias observadas, ampliando de este modo la posibilidad de encontrar más ER. Los resultados de este experimento adicional apoyan nuestra hipótesis, sin embargo, son necesarios experimentos diseñados para demostrar si el efecto de este tratamiento es sólo cualitativo o si es significativo a nivel estadístico (ver Ilustración 6). 


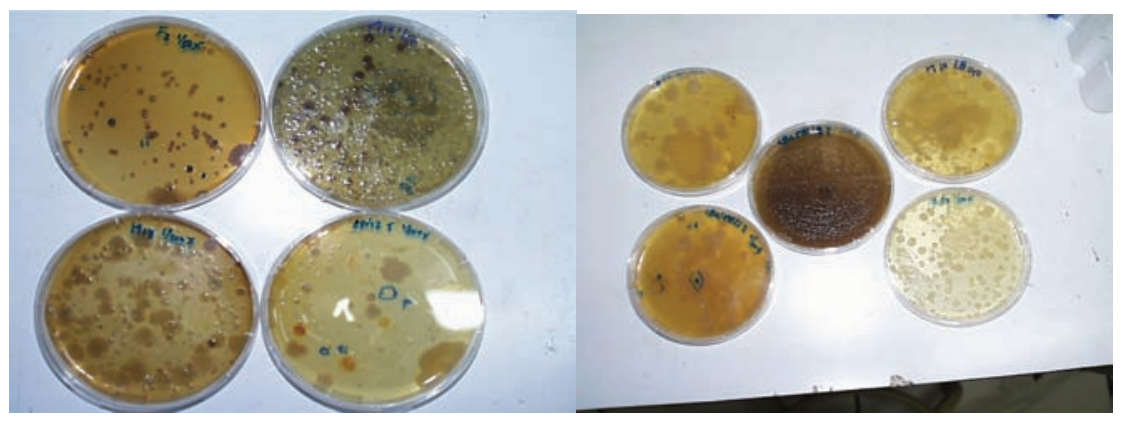

Ilustración 6. Diferencias en número y diversidad de colonias bacterianas en medio de cultivo enriquecido (izquierda) y no enriquecido (derecha).

Las diferencias que se observan son: en medio enriquecido (izquierda) hay mayor número de colonias bacterianas morfológicamente diferentes en cuanto al color y la forma, además la separación entre colonias ayuda a realizar un aislamiento más preciso. En medio no enriquecido (derecha) el crecimiento expansivo de colonias satélites (invasoras) no permite el crecimiento de más colonias bacterianas y hace difícil el aislamiento de colonias puras.

\subsection{Cultivos bacterianos a temperaturas de 55 y $60^{\circ} \mathrm{C}$}

Se observaron diferencias en la cantidad y diversidad de colonias bacterianas cultivadas entre los sítios en estudio, debidas probablemente a las características ambientales del sitio de muestreo (ver Cuadro 4).

Cuadro 4. Número de colonias que crecieron en medio de cultivo enriquecido y no enriquecido correspondiente al muestreo realizado en la cordillera volcánica Los Maribios.

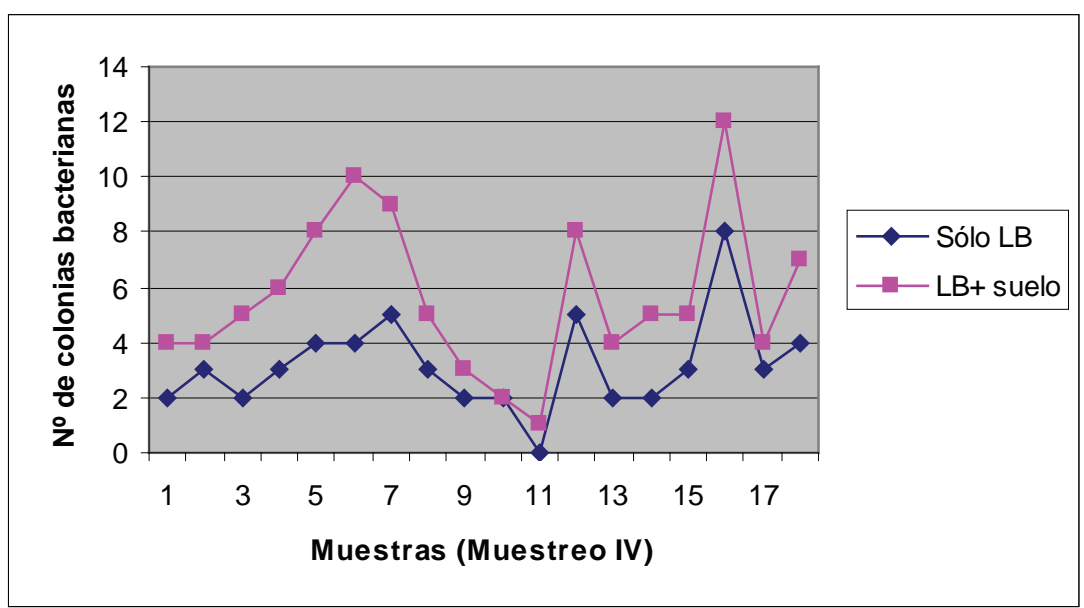

En el muestreo realizado en la cordillera volcánica Los Maribios, es notable el aumento del número y diversidad de colonias bacterianas -en especial termófilas- aisladas en comparación con los demás muestreos. Esto se debe a que ésta es una zona volcánica 
constantemente expuesta a temperaturas altas y en ciertos sitios, como las fumarolas, respiraderos o cráteres, las temperaturas pueden ser superiores a los $50^{\circ} \mathrm{C}$. También, se constató que se puede aislar bacterias termófilas (aunque en menor cantidad) de ambientes no necesariamente termófilos a como lo describen Rhaman et al. (2004).

La bioprospección de la biodiversidad permite conocer e investigar los recursos biológicos de nuestro país y su uso con fines comerciales, dando mayor valor a los recursos naturales e incentivando la conservación de la diversidad biológica nicaragüense. Aunque se han identificado numerosas ER -de las cuales están disponibles comercialmente aproximadamente 250- hay una constante necesidad de enzimas adicionales que reconozcan nuevas secuencias de $\mathrm{ADN}$, facilitando mayor flexibilidad para la manipulación genética y permitiendo el desarrollo de aplicaciones especializadas que son de gran interés en la investigación científica y la industria biotecnológica.

El método usado para la identificación de las enzimas es general y rápido. Aunque no se logró la identificación de una ER nueva, no se descartan las probabilidades de encontrarlas en estudios posteriores. Aún así, este método es sensible porque permitió el aislamiento de ER en bacterias de distintos ambientes y distintas especies bacterianas.

De mucha relevancia en este estudio es la disponibilidad de los datos de los isoesquizómeros de las ER identificadas en Internet. Específicamente, para las ER, el Dr. Roberts propuso e inició la Base de Datos de Enzimas de Restricción (Restriction Enzyme Database, REBASE) por sus siglas en inglés. REBASE contiene toda la información de importancia acerca de las ER conocidas y provee de herramientas bioinformáticas para su estudio, así como de actualizaciones de las ER nuevas y sus aplicaciones. Se puede acceder a REBASE en el sitio web http://rebase.neb.com/rebase/rebase.html.

Debido a que se identificó isoesquizómeros de enzimas conocidas de acuerdo a patrones de corte y no se identificó a nivel bioquímico ni molecular, sería de mucho interés conocer la diversidad bacteriana presente a nivel de especie. Un abordaje complementario que estamos iniciando en nuestro laboratorio consiste en una búsqueda "racional" de ER. Mediante esto tratamos de identificar posibles genes que codifiquen ER a partir de las bases de datos de genomas secuenciados de bacterias. Una vez identificados por métodos de bioinformática, se subclonan los genes y se expresan en bacterias hospederas. Posteriormente se siguen los ensayos bioquímicos y de biología molecular utilizados en este estudio. Este nuevo abordaje tiene la ventaja de ser más directo que el muestreo aleatorio.

Una utilidad práctica de las bacterias encontradas que tienen ER es que se pueden purificar en nuestro laboratorio a bajo costo y ser utilizada por cualquier investigador en nuestro país. Por otra parte, se trata de crear un banco de ADN bacteriano para posterior análisis y estudios de biodiversidad.

La información de los isoesquizómeros encontrados en Nicaragua fue codificada y registrada en la base de datos REBASE a partir del 2008 (ver Cuadro 3). 


\subsection{La importancia de explorar los ambientes volcánicos extremos}

Nicaragua, con gran variedad de ambientes volcánicos, presenta una posibilidad única de estudiar a profundidad temas científicos como el origen y la evolución de la vida en la tierra y el descubrimiento de nuevos microorganismos que puedan ser útiles como referencia científica y para la industria biotecnológica. Como parte del cordón volcánico del pacífico y con más de 15 volcanes, tanto extintos como activos recientes (volcán Cerro Negro) y con diferentes ambientes volcánicos extremos, se podría promover gran interés para estudios exploratorios con el objetivo de determinar las diferentes variables ambientales para conocer qué tipo de microorganismos extremófilos podríamos encontrar. Relacionado a este tipo de investigación de ambientes volcánicos y su importancia para conocer más sobre la historia de la tierra desde las bio-geociencias, el año 2008 ha sido declarado el "Año Internacional del Planeta Tierra"2. Nos unimos a esta celebración estudiando parte de este sistema en Nicaragua. Algunos programas de investigación a nivel internacional se centran en el estudio de organismos extremófilos tales como Life in Extreme Environments (Vida en ambientes extremos) y Astrobiology (Astrobiología) de la NSF (National Science Foundation) y la NASA (National Aeronautics and Space Administration) de Estados Unidos. Por otro lado, en Europa crearon la European Union's Biotechnology of Extremophiles y Extremophiles as Cell Factories, lo que indica el nivel de importancia que ocupan los estudios de ambientes extremos y su diversidad microbiana para estas agencias de investigación. Los microorganismos extremófilos tienen una gran importancia económica porque han dado origen a industrias biotecnológicas multimillonarias en la agricultura, síntesis química, detergentes y farmacéutica. También la ciencia en general se ha beneficiado del descubrimiento y uso de los organismos extremófilos en dos formas. Primero, al desvelar qué tan extremo puede ser un organismo se han descubierto nuevos grupos taxonómicos, enriqueciendo la filogenética. Segundo, los extremófilos han facilitado datos que son básicos para la biología molecular, entre éstos uno de los más importantes es el estudio del plegamiento de proteínas ${ }^{3}$. El ejemplo más contundente fue el asilamiento de la Taq polimerasa, la enzima que hizo posible la imprescindible técnica de la biología molecular moderna: la PCR (Reacción en cadena de la polimerasa).

Presentamos los resultados de un pequeño trabajo de investigación donde nos centramos en la búsqueda de ER. Sin embargo, contamos con todo un sistema natural por explorar e investigar que podría resultar en una gran oportunidad para el desarrollo científico y económico de Nicaragua y de sus jóvenes científicos.

\section{Agradecimientos}

A New England Biolabs Inc. de Estados Unidos por proveer todas las ER comerciales, ADNs purificados y tampones para los ensayos de identificación. A Nilson Aguilar y Omar Ponce por su colaboración en el trabajo de campo. Al Dr. Richard J. Roberts y Richard Morgan de New England Biolabs por sus aportes en la identificación de algunas actividades enzimáticas. A la Doctora Verónica Díaz del Laboratorio de Genética Molecular de la UNANLeón por la revisión del documento de Tesis presentado por Julio Gómez. 
Notas

1 Trabajo de investigación que incluye datos y resultados presentados en Tesis de graduación de Licenciatura de Biología del investigador Julio Gómez en el año 2007.

2 El Año Internacional del Planeta Tierra es una iniciativa conjunta de la Organización de la Naciones Unidas para la Educación, la Ciencia y la Cultura (UNESCO) y la Unión Internacional de Ciencias Geológicas (IUGS), que tiene como objetivo ayudar a la sociedad a reducir los riesgos de contaminantes naturales y el uso sostenible de los recursos naturales. Para mayor revisión buscar el volumen 451, número 7176, de enero 2008 en Nature: "Year of Planet Earth".

3 Para una revisión más exhaustiva del estudio de los organismos extremófilos favor revisar la serie de artículos de revisión publicados en el volumen 409, número 6823 de febrero 2001 en Nature, "Insight Review articles: Astrobiology".

\section{Referencias bibliográficas}

BUDOWLE, B.; SMITH, J.; MORETTI, T. \& DIZINNO, J. (2000) DNA typing protocols: Molecular biology and forensic analysis. Biotechniques Book. EU: Eaton Publishing.

COLIGAN, J. E.; DUNN, B. M.; SPEICHER, D. W. \& WINGFIELD, P. T. (2003) Short protocols in Protein Science. EU: John Wiley and Sons.

DÍAZ, V.; MUÑIZ, L. M. \& FERRER, E. (2001) "Random amplified polymorphic DNA and amplified fragment length polymorphism assesment of genetic variation in Nicaraguan populations of Pinus oocarpa." Molecular Ecology.vol.10, 2593-2603.

ENGVALL, E. O.; BRANDSTROM, B.; GUNNARSSON, A.; MORNER, T.; WAHLSTROM, H. \& FERMÈR, C. (2002) "Validation of a polymerase chain reaction/ Restriction enzyme analysis methods for species identification of thermophilic Campylobacters isolated from domestic and wild animals". Journal of Applied Microbiology. № 92, 47-54.

EUROPA TECHNOLOGIES LTD. (2007). Imágenes georeferenciadas. Google Earth (4.0.2737) [Software de cómputo]. Google. Obtenidas: junio de 2007.

GEORNARAS, I.; KUNENE, N. F.; HOLY, A. V. \& HASTINGS, J. W. (1999) "Amplified fragment length polymorphism fingerprinting of Pseudomonas strains from a poultry processing plant”. Applied and environmental microbiology. Vol.65: $\mathrm{N}^{0}$ 9.3828-3833.

GREENE, P. \& HEYNEKER, H. (1978) "A general method for the purification of restriction enzymes". Nucleic Acids Research, vol: 5; No 7; 2373-80.

GUEVARA, A. L. (2002) Biodiversidad, Bioprospección y Derechos intelectuales. (En línea). Costa Rica. INBio. Archivo pdf. disponible en www.conicit.go.cr/propiedad intelectual/ anal-guevara.pdf. Consultado: 05 de mayo de 2007.

JENKINS G. J. S.; WILLIAMS G. L; BEYNON, J.; YE, Z.; BAXTER, N. \& PARRY, J. M. (2002) "Restriction enzymes in the analysis of genetic alterations responsible for cancer progression". British Journal of Surgery. N No $^{\circ}$ 89, 8-20.

MARENA(Ministerio del Ambientey Recursos Naturales) (1999)Biodiversity in Nicaragua: A country study. Managua:MARENA.

NEB (2002-03) Catálogo y referencia técnica. EU: New England BioLabs. 
OLIVE, M. D. \& BEAN, P. (1999) "Principles and applications of methods for DNA-based typing of microbial organisms". Journal of Clinical Microbiology.Vol.37, $\mathrm{N}^{\mathrm{o}} 6$ : $1661-$ 1669.

QING, X.; STICKELS, S.; ROBERTS, R.; BLASER, M. \& MORGAN, R. (2000) "Purification of the novel endonuclease, Hpy188I, and cloning of its restriction -modification genes reveal evidence of its horizontal transfer to the Helicobacter pylori genome". The Journal of Biological Chemistry, vol 275, No 22; 17086-17093.

RAHMAN, J. T.; MARCHANT, R. \& BANAT I. M. (2004) "Distribution and molecular investigation of highly thermophilic bacteria associated with cool soil environments". Biochemical Society Transactions: vol.32, part: 2,209-213.

ROBERTS, R. J.; VINCZE, T.; POSFAI, J. \& MACELIS, D. (2005) "REBASE: Restriction enzymes and DNA methyltransferases". Nucleic Acids Research: vol.33: 230-232.

ROBERTS, R. J. (2005) "How restriction enzymes became the workhorses of molecular biology”. Proceedings of the National Academy of Sciences (PNAS). Vol. 102. N 17. pag. 5905-5908

ROUSTAN-ESPINOSA, I.; GUERRERO, D.; FLORES, E. \& HUETE-PÉREZ, J. (2000) "Enzimas de restricción de bacterias nativas de Nicaragua”. Encuentro Año: XXXII; No: 52. 1018.

WATSON, J.; GILMAN, M.; WITKOWSKI, J. \& ZOLLER, M. (1992) Recombinant DNA. $2^{\text {nd }}$ ed. New York: W. H .Freeman \& Company. $2^{\text {da }}$ edición.

WATSON, J.; BAKER, T.; BELL, S.; GANN, A.; LEVINE, M. \& LOSICK, R. (2004) Molecular biology of the gene. San Francisco: Pearson-Benjamin Cumings and Cold Spring Harbor Laboratory Press. $5^{\text {ta }}$ edición.

WHITEHEAD, P. \& BROWN, N. (1985) "A simple method for screening bacteria for type II restriction endonucleases enzymes in Aphanothece halophytica". Archives of Microbiology, vol: 141; 70-74. 